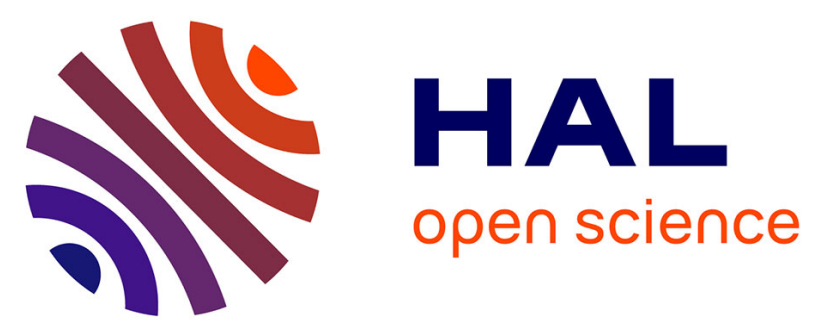

\title{
Prospective randomized double-blind trial of racecadotril compared with loperamide in elderly people with gastroenteritis living in nursing homes
}

Luca Gallelli, Manuela Colosimo, Grazia A. Tolotta, Daniella Falcone, Laura Luberto, Lucia S. Curto, Pierandrea Rende, Francesca Mazzei, Norma M. Marigliano, Giovambattista de Sarro, et al.

\section{To cite this version:}

Luca Gallelli, Manuela Colosimo, Grazia A. Tolotta, Daniella Falcone, Laura Luberto, et al.. Prospective randomized double-blind trial of racecadotril compared with loperamide in elderly people with gastroenteritis living in nursing homes. European Journal of Clinical Pharmacology, 2009, 66 (2), pp.137-144. 10.1007/s00228-009-0751-3 . hal-00612985

\section{HAL Id: hal-00612985 https://hal.science/hal-00612985}

Submitted on 2 Aug 2011

HAL is a multi-disciplinary open access archive for the deposit and dissemination of scientific research documents, whether they are published or not. The documents may come from teaching and research institutions in France or abroad, or from public or private research centers.
L'archive ouverte pluridisciplinaire HAL, est destinée au dépôt et à la diffusion de documents scientifiques de niveau recherche, publiés ou non, émanant des établissements d'enseignement et de recherche français ou étrangers, des laboratoires publics ou privés. 


\title{
Prospective randomized double-blind trial of racecadotril compared with loperamide in elderly people with gastroenteritis living in nursing homes
}

\author{
Luca Gallelli • Manuela Colosimo • Grazia A. Tolotta • Daniella Falcone • \\ Laura Luberto • Lucia S. Curto • Pierandrea Rende • Francesca Mazzei • \\ Norma M. Marigliano • Giovambattista De Sarro • Salvatore Cucchiara
}

Received: 8 September 2009 / Accepted: 18 October 2009/Published online: 10 November 2009

(C) Springer-Verlag 2009

\begin{abstract}
Aim Our aim was to compare the efficacy and tolerability of loperamide and racecadotril in elderly patients with acute diarrhea.

Research design and methods We performed a randomized, prospective, double-blind, and parallel group design implemented in geriatric nursing homes in Catanzaro, Italy, from February 2008 to March 2009. Patients of both sexes were randomly allocated to receive either one tablet of racecadotril $100 \mathrm{mg}$ every $8 \mathrm{~h}$ or two tablets of loperamide $2.0 \mathrm{mg}$ followed by one tablet after each unformed stool, up to four tablets in any 24-h period. Patients were treated until recovery, defined as the production of two consecutive normal stools or no stool production for a period of $12 \mathrm{~h}$. Results Normal stools were collected $36 \pm 4 \mathrm{~h}$ after the beginning of racecadotril and in $63 \pm 6 \mathrm{~h}$ from the beginning of loperamide administration $(P<0.01)$. The median time of abdominal pain in the intent-to-treat (ITT) population was
\end{abstract}

L. Gallelli · G. A. Tolotta • P. Rende $\cdot$ N. M. Marigliano $\cdot$

G. De Sarro

Chair of Pharmacology, School of Medicine and Surgery,

Department of Experimental and Clinical Medicine,

University Magna Graecia of Catanzaro,

Mater Domini University Hospital,

Catanzaro, Italy

M. Colosimo $\cdot$ F. Mazzei $\cdot$ N. M. Marigliano Geriatric Nursing Home "Madonna di Porto",

Catanzaro, Italy

D. Falcone $\cdot$ L. S. Curto

Chair of Molecular Biology, School of Medicine and Surgery

Department of Experimental and Clinical Medicine,

University Magna Graecia of Catanzaro,

Mater Domini University Hospital,

Catanzaro, Italy
$14 \mathrm{~h}$ for racecadotril and $28 \mathrm{~h}$ for loperamide. In the perprotocol (PP) population, the median time of abdominal pain was $14 \mathrm{~h}$ for racecadotril and $32 \mathrm{~h}$ for loperamide $(P<0.01)$. About the $50 \%$ of patients experienced at least one adverse event during the study: $12 \%$ in the racecadotril group and $60 \%$ in the loperamide group. The most frequently occurring adverse events were nausea and constipation. Genetic analysis did not report the presence of rapid or poor metabolizers. Pharmacoeconomic analysis performed at the end of our study documented an increase in costs in the loperamide group with respect to the racecadotril group $(P<0.01)$.

Conclusions Racecadotril is more effective than loperamideprobably due to drug interaction with loperamide-and it is not related to pharmacogenetic susceptibility. Racecadotril is also more cost effective than loperamide.

Keywords Acute diarrhea - Gastroenteritis · Elderly patients $\cdot$ Racecadotril $\cdot$ Loperamide

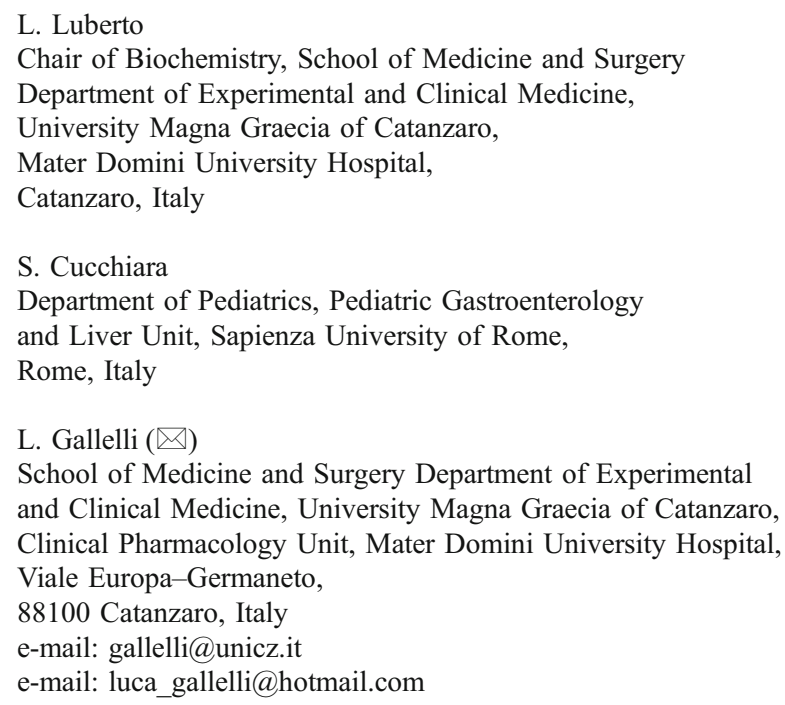




\section{Introduction}

Gastroenteritis is an inflammation of the gastrointestinal tract involving both the stomach and the small intestine and resulting in acute diarrhea. Inflammation is caused most often by infection with certain viruses and less often by bacteria or their toxins, parasites, or adverse reaction to something in the diet or drugs [1]. Whereas gastroenteritis normally has a mild clinical course, hospitalization and death are more common among elderly people, particularly those who live in geriatric nursing homes. In fact, gastroenteritis will occur in settings where people gather, even when standards of care and food hygiene are very high [2]. Several factors, such as the physiological decrease in gastric acid secretion, are involved in the increased vulnerability to diarrhea in elderly people. Other factors, such as decreased motility of the gastrointestinal tract; reduced immune response; residence in nursing homes, retirement communities, and hospitals with crowded conditions; and a possible increased mucosal sensitivity to toxins; all carry greater risk to the elderly [3, 4]. Some infections are inevitable due to the susceptibility of the population and the highly infectious and persistent nature of enteric pathogens. Several enteropathogenic viruses, i.e., caliciviruses, norovirus, and rotavirus, are the most common causal agents in acute gastroenteritis outbreaks [5, 8].

Gastroenteritis usually appears with acute diarrhea, abdominal pain, and vomits. Acute diarrhea represents a common clinical problem in developed countries and epidemic plague in underdeveloped nations. It is calculated to be responsible worldwide for approximately 2 million deaths per year [9]. In the United States, approximately half those who die of diarrhea are of advanced age to 74 years, with increased total mortality about 400 times greater than other ages [10].

Managing an elderly patient with diarrhea must ensure proper hydration using available oral rehydration solutions (ORS) [11, 12]. In many patients, however, this is not possible due to their decreased ability to drink. Therefore, other approaches may be used in reduce the risk of dehydration and systemic or metabolic diseases. Available drugs are represented by loperamide and racecadotril. Loperamide is an mu-opiate-receptor agonist, which prolongs orocecal and colonic transit times by disrupting the gut's electrical activity, increasing gut capacity, and delaying the passage of fluids through the small intestine [13]. Racecadotril, an enkephalinase inhibitor, is an indirect delta receptor agonist, with antisecretory activity [14, 15] without activity on gut muscle [16].

The aim of this study was to compare the efficacy and tolerability of loperamide and racecadotril in elderly patients residing in a geriatric nursing home who had severe acute diarrhea. Moreover, to evaluate the role of metabolism in both efficacy and tolerability, we evaluated cytochrome P450 polymorphisms. Finally, at the end of the study, we performed a pharmacoeconomic evaluation of both treatment regimens.

\section{Methods}

The study was a randomized, prospective, double-blind, and parallel group design implemented geriatric nursing homes in Catanzaro, Italy, from February 2008 to March 2009. Eligible patients were women and men with acute diarrhea (defined as three or more liquid stools in $24 \mathrm{~h}$ ), without signs of severe dehydration (sunken eyes, reduced skin turgor, lethargy, unable to drink, and absent/uncountable radial pulse) and bacterial infection (i.e., the presence of blood or pus in their stool). Patients were excluded if they met any of the following conditions: presence of chronic or iatrogenic diarrhea, temperature $>38.6^{\circ} \mathrm{C}$, signs or symptoms of orthostatic hypotension, inability to take medications and fluids by mouth; a history of chronic gastrointestinal tract disease, hepatic or renal insufficiency, or a history of hypersensitivity to loperamide or racecadotril. Finally, patients who had taken any antidiarrheal or antimicrobial drugs in the 5 days prior to the study, and patients with concomitant illnesses requiring antibiotic treatment, were not eligible.

\section{Experimental protocol}

Patients with acute diarrhea and without regard for age, sex, or medical history were randomly allocated to receive either one tablet of racecadotril $100 \mathrm{mg}$ every $8 \mathrm{~h}$ or two tablets of loperamide $2.0 \mathrm{mg}$ followed by one tablet after each unformed stool, up to four tablets in any 24-h period. For the randomization, was used a computer program to generate a sequence of treatment allocations by block randomization using a random number generator. Investigators were blinded to the block size to avoid selection bias. Each treatment was started after the third diarrhea episode and was stopped after the production of two consecutive normal stools or no stool production for a period of $12 \mathrm{~h}$. In order to exclude gut infection, before treatment in both groups, a sample of fresh stool was collected for microbiological analysis. If recovery did not occur within 4 days, the treatment was discontinued and, in order to avoid dehydration, the patient was treated with other drugs. Each dose of the medication was taken under the supervision of a designated study physician. Time, number, and type of stool were recorded, as were the occurrence of adverse signs and symptoms. In both groups, $750 \mathrm{ml}$ of a standard ORS [sodium $(\mathrm{Na}+) 90 \mathrm{mmol} / \mathrm{l}$, chlorine $(\mathrm{Cl} 2) 80 \mathrm{mmol} / \mathrm{l}$, potassium $(\mathrm{K}+) 20 \mathrm{mmol} / \mathrm{l}$, 
citrate $10 \mathrm{mmol} / \mathrm{l}$, and glucose $111 \mathrm{mmol} / \mathrm{l}$ ] was given to all patients every day. The study was approved by Ethics Committee and was conducted in accordance with the Declaration of Helsinki. Written informed consent was received from each patient. For patients with senile dementia, consent was obtained from a partner.

\section{Microbiological analysis}

Fresh stool samples were collected at the beginning of the study by the nursing staff and sent for routine microbiological analysis for Salmonella spp., Shigella spp., Yersinia spp., Vibrio spp., Campylobacter spp., Staphylococcus aureus and intestinal parasites (helminthes and protozoa), according to standard protocols.

\section{Evaluations}

The primary efficacy criterion was the duration of diarrhea in days, from the first treatment dose to recovery. Secondary efficacy criterion consisted of duration of other symptoms, i.e., abdominal pain and abdominal distension. The overall clinical response during the study was assessed by physicians who were blinded to the treatment. Stool output, electrolytes, fluid intake, body weight, and hematocrit were also evaluated weekly in both groups. Stool output was calculated as the sum of the weights of the watery and loose stools (diarrheic stools) divided by the body weight at base line. Tolerability and safety were assessed by recording the adverse events experienced during treatment and by the occurrence of constipation. Signs and symptoms evaluated were pain on abdominal palpation, anorexia, nausea, and anal burning. A visual analogue scale (VAS) was used to assess pain severity before, during, and after treatment. Pharmacoeconomic evaluation was performed at the end of study period, and both intent-to-treat (ITT) and per-protocol (PP) costs of drug treatments only were analyzed. We did not consider indirect costs, because patients were residing in nursing homes, with both physicians and nursing staff presents every day. We estimated the cost of the drugs using average wholesale prices. Racecadotril (20 tablets of $100 \mathrm{mg}$ ) was estimated at 11.50 euros $(0.575$ euros for each tablet), and the price of loperamide (15 tablets of $2 \mathrm{mg}$ ) was 5 euros ( 0.33 euros for each tablet). The defined daily dose, which represents the assumed average daily dose of a drug when used for its main indication in adults, was 1.725 euros for racecadotril and 1.65 euros for loperamide (a mean of five tablets/day). To evaluate the role of genetic polymorphisms in cytochrome P450 involved in drug metabolism, a blood sample was taken from each patient at the beginning and end of the study period. Finally, we analyzed polymorphisms in patients nonresponsive to treatment and in patients who developed side effects.

\section{Statistical analysis}

Statistical analysis was performed using SPSS. Both ITT and PP analyses were performed for primary and secondary parameters. Estimates of the survival distribution of the duration of diarrhea were analyzed using Kaplan-Meier survival analysis techniques. The overall clinical response of the treatment groups was compared using the Cochran-Mantel-Haenszel test, as was the comparison of treatment group changes from inclusion to the end of treatment.

\section{Results}

Patient characteristics

During the study period, 61 patients (19 men and 42 women) were enrolled for ITT and randomized in two groups; 30 (nine men and 21 women) were treated with racecadotril, whereas 31 patients (ten men and 21 women) received loperamide (data not shown). At the end of the study, 54 patients participated fully, making up the PP population (88.5\%). Two patients (3.27\%) did not complete the study due to adverse events, three $4.9 \%$ ) were considered noncompleters due to deviation from protocol, and two $(3.27 \%)$ were lost to follow-up. Mean ages were 82.9 (range 73-96) years for the racecadotril group and 81.9 (range 73-93) years for the loperamide group (Fig. 1). Other variables with regard to body weight, duration of diarrhea, and fluid intake were comparable between the two groups. All patients presented polytherapy, but pharmacological evaluation performed by a specialist excluded that drug treatments may be involved in the development of diarrhea. Microbiological investigation performed on fresh stool taken before treatment documented that fecal specimens were negative for bacterial enteropathogens and intestinal parasites (data not shown).

\section{Symptoms and stool normalization}

During the study period, the racecadotril group experienced a mean of 3.93 episodes of acute diarrhea [range 1-11 episodes; standard deviation (SD) 2.99] after they had met the inclusion criteria (three episodes in $24 \mathrm{~h}$ ), and a mean of 7.29 in the loperamide group (range $2-16$ episodes; SD 4.45) (data not shown). We defined an episode as all diarrhea manifestations in each patient from the beginning of stool output alteration up to stool output normalization. Before the beginning of the treatment, in both groups, stool 


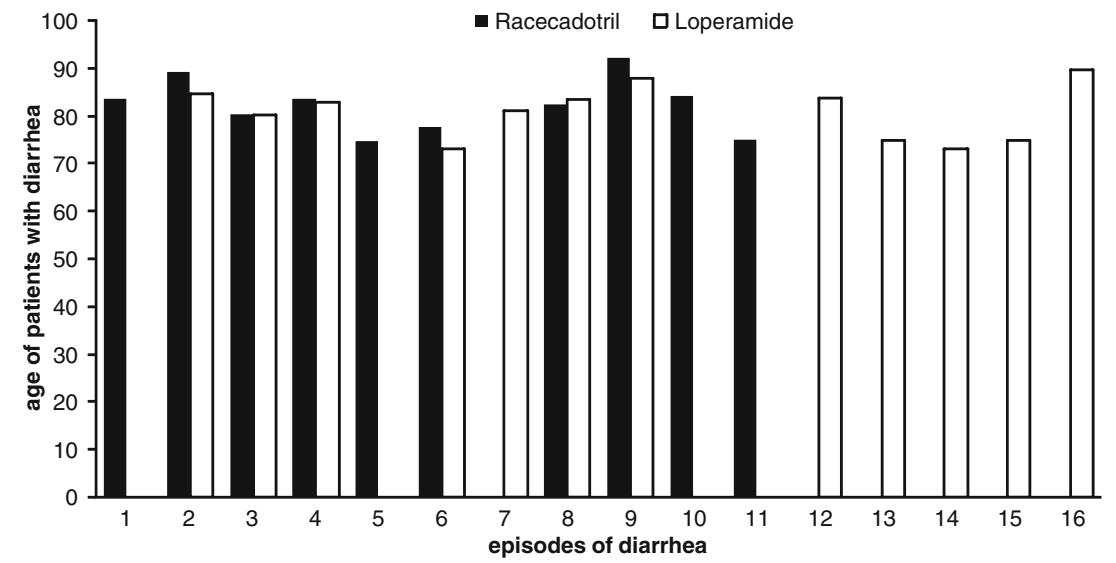

Fig. 1 Mean patient age during all episodes of diarrhea in both racecadotril (black) and loperamide (white) treatment groups

output comprised between 260 and $270 \mathrm{~g} / \mathrm{kg}$. In both group, all episodes of diarrhea were more common in women, with no difference in the median age (Fig. 1). The mean duration of abdominal pain in the ITT population was $14 \pm$ $1 \mathrm{~h}$ for racecadotril and $28 \pm 1 \mathrm{~h}$ for loperamide. In the PP population, the mean duration of abdominal pain was $14 \pm$ $1 \mathrm{~h}$ for racecadotril and $32 \pm 2 \mathrm{~h}$ for loperamide $(P<0.01)$. In all episodes, normal stools were collected $36 \pm 4 \mathrm{~h}$ after the beginning of racecadotril and $63 \pm 6 \mathrm{~h}$ from the beginning of loperamide $(P<0.01)$ (data not shown). Mean total stool output before recovery was $120 \pm 27 \mathrm{~g} \mathrm{~kg}$ in the racecadotril group and $150 \pm 39 \mathrm{~g} / \mathrm{kg}$ in the loperamide group, a 25 percent lower output with racecadotril $(P<0.01)$. In about $50 \%$ of patients (age $80 \pm$ 0.2 years; range $73-93$ years), in the loperamide group during the study period, 4 days of treatment were ineffective. Therefore, patients were treated, after a new negative microbiological evaluation, with racecadotril, with a rapid normalization of all symptoms. There were no statistically significant differences between the two treatment groups for the major outcome variables: ORS intake and need for unscheduled intravenous fluids.

\section{Adverse drug reactions}

About $50 \%$ of patients experienced at least one adverse event during the study: $12 \%$ in the racecadotril group and $60 \%$ in the loperamide group. The most frequently occurring adverse events were nausea and constipation. In particular, nausea occurred in $10 \%$ of patients treated with racecadotril and $20 \%$ of patients treated with loperamide; constipation was observed in $15 \%$ of patients in the racecadotril group and in $60 \%$ in the loperamide group. Adverse events noted as per protocol, such as abdominal pain, headache, anorexia, etc., were not different between groups. During the study, at the end, and at follow-up, no electrolyte alterations were recorded in either group.

\section{Genetic evaluation}

To evaluate the role of cytochrome (CYP) metabolism in loperamide failure, blood of patients not responsive to loperamide was analyzed for the main allelic variants of the CYP450 isoforms 3A4/5 and CYP2C8. CYP2C8 and allelic variants of CYP3A4 genes were analyzed with real-time reverse-transcriptase polymerase chain reaction (PCR) by TaqMan kits purchased from Applied Biosystems. Patients did not carry any detrimental CYP2C8 or CYP3A4 allele. Furthermore, they did not carry extra copies of functional alleles CYP2C8 or CYP3A4; therefore, they were not genetically classifiable as ultrarapid or poor metabolizers for these two enzymes.

\section{Pharmacoeconomic evaluation}

Pharmacoeconomic analysis performed at the end of our study documented an increase in costs in the loperamide group with respect to racecadotril. Based on the ITT analysis, costs average in the racecadotril group was 44.85 euros and for the loperamide group 91.99 euros (Fig. 2).

Based on PP analysis, mean cost of treatment was 44.85 euros in the racecadotril group compared with 107.5 euros for the loperamide group (Fig. 2). Based on both ITT and PP analysis, loperamide treatment was associated with an incremental total cost (Fig. 2).

\section{Discussion}

In this study, we evaluated the effects of loperamide and racecadotril on acute diarrhea in elderly people living in nursing homes. There are multiple causes of gastroenteritis and acute diarrhea, including ingestion of toxins, food intolerance, psychological stress, and adverse reactions to medications. In most cases, the cause is thought to be 

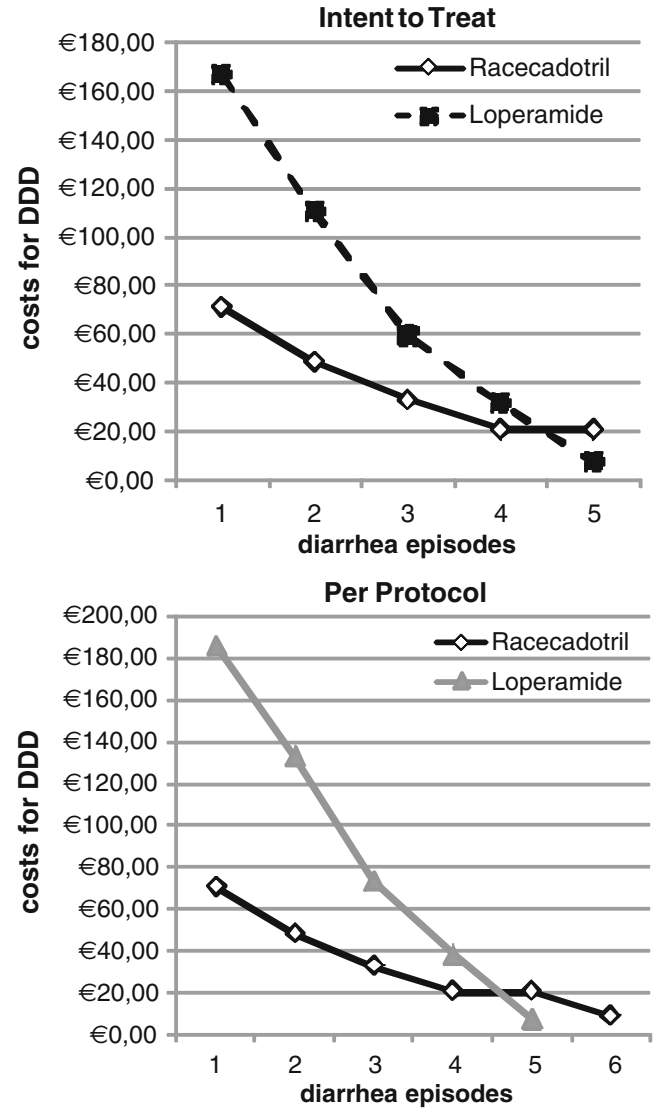

Fig. 2 Estimated cost for defined daily dose $(D D D)$ of both racecadotril and loperamide treatments for each episodes of diarrhea calculated as intent to treat (ITT) (up) and per protocol (PP) (down). We define an episode of diarrhea as all diarrhea manifestations in each patient from stool output alteration to stool output normalization

infections, including those caused by viruses, bacteria, or parasites [17, 18]. Viruses are more important in infants (rotaviruses) [19-21] and cause community foodand water-borne gastroenteritis (noroviruses) in all age groups $[22,23]$. In health-care facilities, transmission can additionally occur through hand transfer of the virus to the oral mucosa via contact with materials, vomits, and environmental surfaces that have been contaminated with either feces or vomits. These circumstances make it extremely difficult to control outbreaks in institutional settings $[24,25]$.

In developing countries, bacterial enteropathogens, i.e., salmonella, shigella, Campylobacter jejuni, enteropathogenic Escherichia coli, and vibrio cause just under half of all cases of endemic pediatric diarrhea and approximately half the cases of diarrhea among international travelers to these areas [26]. In our study, we enrolled 61 elderly patients residing in a geriatric nursing home who had no signs and symptoms of acute bacterial gastroenteritis. To exclude further patients with bacterial diarrhea, a microbiological analysis of fresh stool was taken from each patient before treatment. Microbiological analysis excluded the presence of bacterial enteropathogens or intestinal parasites.

Usually, the pathophysiological problem of acute diarrhea due to nonbacterial agents is induced by hypersecretion of intestinal mucosa. Therefore, the ideal treatment for acute diarrhea should combine replacement ORS and drugs able to modulate intestinal hypersecretion or gastrointestinal transit, such as racecadotril and loperamide. Both racecadotril and loperamide are rapid, equally effective, treatments for acute diarrhea in adults [27], do not penetrate the nervous system, and have no substantial potential for addiction. However, they have several differences in pharmacodynamic and pharmacokinetic parameters. Racecadotril, a specific enkephalinase inhibitor, prevents inactivation of endogenous enkephalins and prolongs their physiologic action. Enkephalins act as neurotransmitters in the gastrointestinal tract by activating delta-opiate-receptors and thus reducing the level of cyclic adenosine monophosphate (AMP) [28]. The result is a low secretion of water and electrolytes without any detectable effect on intestinal motility $[16,29]$. The efficacy and safety of racecadotril as an adjuvant to ORS therapy were documented several years ago in infants and children with less severe diarrhea [30] and in children with rotavirusassociated diarrhea [31]. Hamza et al. [32] and Vetel et al. [33] reported that racecadotril produced a significant $(P=0.025)$ decrease in stool weight during the first day of treatment compared with placebo and was also associated with significantly fewer diarrheic stools than placebo after 1 day of treatment. Other studies in adult patients reported that racecadotril was able to reduce diarrhea in about 19 $\mathrm{h}[27,34]$. In agreement with these studies, we documented that racecadotril reduced diarrhea in all patients in about 1 day in all episodes of gastroenteritis. No ineffectiveness was recorded during this treatment. Loperamide is a selective mu-opiate-receptor agonist that is able to prolong orocecal and colonic transit times by disrupting the gut's electrical activity, increasing gut capacity, and delaying the passage of fluids through the small intestine [35]. Several studies reported that loperamide is able to reduce diarrhea manifestations in adults, with or without antibiotic treatments [36].

Of the 61 patients randomized in our study (ITT population), 54 (28 in the racecadotril group and 26 in the loperamide group) were considered valid as per protocol. Three patients with moderate Alzheimer's dementia ([Mini Mental State Examination (MMSE) score of 15] were excluded for the impossibility of evaluating abdominal pain intensity with the VAS scale and also evaluating the impact of side effects. We documented that loperamide reduced diarrhea in about 3 days in all episodes of gastroenteritis. However, in about $50 \%$ of treated patients over the entire treatment period, it was ineffective. The percentage of 
ineffectiveness was significantly higher in the third and in the fourth episode of gastroenteritis. The low efficacy of loperamide in our study could be related to a metabolic reaction due to drug interactions. Loperamide is mainly metabolized to desmethyl loperamide (DLOP) through the $\mathrm{N}$-demethylation pathway [37, 38], and clinical studies have shown that DLOP formed by LOP N-demethylation is a major metabolite of LOP in humans [39, 40]. Moreover, it has been demonstrated that CYP2B6, CYP2C8, CYP2D6, and CYP3A4 catalyze LOP N-demethylation in human liver microsomes, and among them, CYP2C8 and CYP3A4 may play a crucial role in loperamide $\mathrm{N}$-demethylation at therapeutic concentrations [41]. Moreover, loperamide is a glycoprotein $\mathrm{P}$ substrate; therefore, its absorption in the bowel may be related to drug coadministration. Therefore, it is possible that drug interaction may modify loperamide elimination in humans. In fact, concurrent administration with CYP3A4 inhibitors such as fluvoxamine or erythromycin may lead to clinically significant reductions in plasma loperamide concentrations. Moreover, it is possible that the coadministration of a CYP3A4 enzyme inducer (such as carbamazepine or phenobarbital) may reduce loperamide effectiveness. In our study, all patients were in polytherapy with omeprazole, esomeprazole, antidepressants, or anitarrhythmics, which are inhibitors of CYP3A4 and glycoprotein $\mathrm{P}$, as well as with phenobarbital, which is a CYP3A4 inductor. Therefore, we postulate that the loperamide ineffectiveness could be related to drug interaction. In contrast, racecadotril is a prodrug that is quickly metabolized by hydrolysis to its active metabolite, thiorphan, which in turn mediates enkephalinase inhibition [42]. Therefore, in our study, racecadotril induced rapid remission of diarrhea (1-day treatment), because its action was not modified by polytherapy.

Adverse drug reactions (ADRs) represent a major public health problem in older populations [43]. Bejer and de Blaey [44] reported that the proportion of admissions related to ADRs in older people was four times higher than in younger people. In addition, we documented that ADRs are more common in elderly patients than in the young [45-48]. It was recently reported that comorbidity could predict repeat admission for ADRs in older adults [49]. The mu-opiate-receptor agonist, loperamide, and other opiates, may cause adverse effects such as reactive constipation and abdominal distension [50]. Their mode of action is through disrupting forward propulsive motility, increasing gut capacity, and delaying passage of fluid through the intestine [51, 52].

In agreement with another study [34], we found that in racecadotril treatment, abdominal distension vanished rapidly, and reactive constipation was less frequent with respect to the loperamide group. These differences can be accounted for by the distinct mechanisms of antidiarrheal activity of the two drugs as above described. In both treatment groups, we documented the development of nausea, which was more frequently in the loperamide group than in the racecadotril group, but it did not cause treatment cessation. Efficacy and side effects may be related both to drug interaction and to genetic polymorphism. Recently, we documented that CYP2D6 polymorphism reduces the effectiveness of opiate agonists in polydrug abuse [53]. To exclude the possibility that loperamide ineffectiveness could be related to gene polymorphism, we performed a pharmacogenetic analysis of CYP3A4 and CYP2C8 expression in unresponsive patients and in patients who developed side effects. Genetic analysis did not identify rapid or poor metabolizers; therefore, we can exclude that genetic susceptibility may be related to loperamide ineffectiveness or loperamide-related side effects in our analysis.

Side effects and drug ineffectiveness are responsible for a significant increase in direct costs during loperamide treatment. In fact, the direct cost of loperamide treatment was 367.95 euros compared with 179.4 euros for racecadotril treatment in ITT analysis. Moreover, the number of stool episodes was higher in the loperamide group compared with the racecadotril group, which influenced the decision switch all patients to racecadotril. Therefore, in PP analysis, loperamide treatment was not cost effective compared with racecadotril (430.05 euros for the loperamide group and 179.04 euros for the racecadotril group). This study was performed in nursing-home residents, so we assumed that indirect costs were similar in both groups.

In conclusion, we found that racecadotril is more effective than loperamide in elderly patients-which may be related to drug interaction with loperamide - and racecadotril is not dependent on pharmacogenetic susceptibility. It is also more cost effective than loperamide. Therefore, in elderly patients with diarrhea, racecadotril could be the first therapeutic option after ORS therapy to reduce the risk of dehydration.

\section{References}

1. Aranda-Michel J, Giannella RA (1999) Acute diarrhea: a practical review. Am J Med 106:670-676. doi:10.1016/S0002-9343(99) 00128-X PMID 10378626

2. Frenzen PD (2003) Mortality due to gastroenteritis of unknown etiology in the United States. J Infect Dis 187:441-452. doi:10.1086/368097 PMID: 12552428

3. Hunter KF, Cyr D (2006) Pharmacotherapeutics in older adults. J Wound Ostomy Continence Nurs 33:630-636 PMID: 17108773

4. Shaojun S, Morike K, Klotz U (2008) The clinical implications of ageing for rational drug therapy. Eur J Clin Pharmacol 64:183189 PMID: 9782630

5. Evans HS, Madden P, Douglas C, Adak GK, O'Brien SJ, Djuretic T, Wall PG, Stanwell-Smith R (1998) General outbreak of 
infectious disease in England and Wales: 1995 and 1996. Commun Dis Public Health 1:165-171 PMID: 9782630

6. Edmonson LM, Ebbert JO, Evans JM (2000) Report of a rotavirus outbreak in an adult nursing home population. J Am Med Dir Assoc 1:175-179 PMID: 12816557

7. Huh JW, Kim WH, Moon SG, Lee JB, Lim YH (2009) Viral etiology and incidence associated with acute gastroenteritis in a 5year survey in Gyeonggi province, South Korea. J Clin Virol 44:152-156. doi:10.1016/j.jcv.2008.11.016 PMID: 19131274

8. Nilsson M, Svenungsson B, Hedlund K-O, Uhnoo I, Lagergren A, Akre T, Svensson L (2000) Incidence and genetic diversity of group c rotavirus among adults. J Infect Dis 182:687-684. doi:10.1086/315772 PMID: 10950759

9. Kosek M, Bern C, Guerrant RL (2003) The global burden of diarrhoeal disease, as estimated from studies published between 1992 and 2000. Bull World Health Organ 81:197-204. doi:10.1590/S0042-96862003000300010 PMID: 12764516

10. Bennett RG, Greenough WB 3rd (1993) Approach to acute diarrhea in the elderly. Gastroenterol Clin North Am 22:517-533 PMID: 8406728

11. Slotwiner-Nie PK, Brandt LJ (2001) Infectious diarrhea in the elderly. Gastroenterol Clin North Am 30:625-635 PMID: 11586549

12. Trinh C, Prabhakar K (2007) Diarrheal diseases in the elderly. Clin Geriatr Med 23:833-856. doi:10.1016/j.cger.2007.06.005 PMID: 17923341

13. Shahbazian A, Heinemann A, Schmidhammer H, Beubler E, Holzer-Petsche U, Holzer P (2002) Involvement of mu- and kappa-, but not delta-, opioid receptors in the peristaltic motor depression caused by endogenous and exogenous opioids in the guinea-pig intestine. Br J Pharmacol 135:741-750. doi:10.1038/sj. bjp.0704527 PMID: 11834622

14. Huijghebaert S, Awouters F, Tytgat GNJ (2003) Racecadotril versus loperamide: antidiarrheal research revisited. Dig Dis Sci 48:239-250. doi:10.1023/A:1021989606317 PMID: 12643598

15. Prado D, Global Adult Racecadotril Study Group (2002) A multinational comparison of racecadotril and loperamide in the treatment of acute watery diarrhoea in adults. Scand J Gastroenterol 37:656-661 PMID: 12126242

16. Bergmann JF, Chaussade S, Couturier D, Baumer P, Schwartz JC, Lecomte JM (1992) Effects of acetorphan, an antidiarrhoeal enkephalinase inhibitor, on oro-caecal and colonic transit times in healthy volunteers. Aliment Pharmacol Ther 6:305-313 PMID: 1350927

17. Guerrant RL, Bobak DA (1991) Bacterial and protozoal gastroenteritis. N Engl J Med 325:327-340 PMID: 2057037

18. Blacklow NR, Greenberg HB (1991) Viral gastroenteritis. N Engl J Med 325:252-264 PMID: 1647494

19. de Wit MA, Koopmans MP, Kortbeek LM, Wannet WJ, Vinjé J, van Leusden F, Bartelds AI, van Duynhoven YT (2001) Sensor, a population-based cohort study on gastroenteritis in the Netherlands: incidence and etiology. Am J Epidemiol 154(7):666-674

20. DuPont HL (2005) What's new in enteric infectious diseases at home and abroad. Curr Opin Infect Dis 18:407-412 PMID: 16148527

21. Marsella M, Raimondi L, Bergamini M, Sprocati M, Bigi E, De Sanctis V, Borgna-Pignatti C, Gabutti G (2009) Epidemiology of rotavirus-associated hospital admissions in the province of Ferrara, Italy. Eur J Pediatr. [PMID: 19255784]

22. Chadwick PR, McCann R (1994) Transmission of a small round structured virus by vomiting during a hospital outbreak of gastroenteritis. J Hosp Infect 26:251-259 PMID: 7915285

23. Parashar U, Quiroz ES, Mounts AW, Monroe SS, Fankhauser RL, Ando T, Noel JS, Bulens SN, Beard SR, Li JF, Bresee JS, Glass RI (2001) "Norwalk-like viruses". Public health consequences and outbreak management. MMWR Recomm Rep 50:1-17
24. Said MA, Perl TM, Sears CL (2008) Healthcare epidemiology: gastrointestinal flu: norovirus in health care and long-term care facilities. Clin Infect Dis 47:1202-1208. doi:10.1086/592299 PMID: 18808354

25. Cheesbrough JS, Green J, Gallimore CI, Wright PA, Brown DW (2000) Widespread environmental contamination with Norwalklike viruses (NLV) detected in a prolonged hotel outbreak of gastroenteritis. Epidemiol Infect 125:93-98 PMID: 11057964

26. Jiang ZD, Lowe B, Verenkar MP, Ashley D, Steffen R, Tornieporth N, von Sonnenburg F, Waiyaki P, DuPont HL (2002) Prevalence of enteric pathogens among international travelers with diarrhea acquired in Kenya (Mombasa), India (Goa), or Jamaica (Montego Bay). J Infect Dis 185:497-502

27. Wang HH, Shieh MJ, Liao KF (2005) A blind, randomized comparison of racecadotril and loperamide for stopping acute diarrhea in adults. World J Gastroenterol 11:1540-1543 PMID: 15770734

28. Rachmilewitz D, Karmeli F, Chorev M, Selinger Z (1983) Effect of opiates on human colonic adenylate cyclase activity. Eur J Pharmacol 93:169-173 PMID: 6580173

29. Shook JE, Lemcke PK, Gehrig CA, Hruby VJ, Burks TF (1989) Antidiarrhoeal properties of supraspinal $\mathrm{mu}$ and delta and peripheral mu, delta and kappa opioid receptor: Inhibition of diarrhea without constipation. J Pharmacol Exp Ther 249:83-90 PMID: 2540324

30. Cézard JP, Duhamel JF, Meyer M (1996) Efficacy and tolerance of acetorphan in infant acute diarrhea: a multicentric, double blind study. Gastroenterology 110(Suppl):A795 Abstract

31. Salazar-Lindo E, Santisteban-Ponce J, Chea-Woo E, Gutierrez M (2000) Racecadotril in the treatment of acute watery diarrhea in children. N Engl J Med 343:463-467 PMID: 10944563

32. Hamza H, Ben Khalifa H, Baumer P, Berard H, Lecomte JM (1999) Racecadotril versus placebo in the treatment of acute diarrhoea in adults. Aliment Pharmacol Ther 13(Suppl 6):15-19 PMID: 10646047

33. Vetel JM, Berard H, Fretault N, Lecomte JM (1999) Comparison of racecadotril and loperamide in adults with acute diarrhoea. Aliment Pharmacol Ther 13(Suppl 6):21-26 PMID: 10646048

34. Rouge J, Baumer P, Berard H, Schwartz JC, Lecomte JM (1993) The enkephalinase inhibitor, acetorphan, in acute diarrhea: a double-blind control clinical trial versus loperamide. Scand J Gastroenterol 28:352-354 PMID 8488368

35. Basilisco G, Camboni G, Bozzani A, Paravicini M, Bianchi PA (1987) Oral naloxone antagonizes loperamide-induced delay of orocecal transit. Dig Dis Sci 32:829-832 PMID: 3608730

36. Riddle MS, Arnold S, Tribble DR (2008) Effect of adjunctive loperamide in combination with antibiotics on treatment outcomes in traveler's diarrhea: a systematic review and meta-analysis. Clin Infect Dis 47:1007-1014. doi:10.1086/591703 PMID: 18781873

37. Miyazaki H, Nambu K, Matsunaga Y, Hashimoto M (1979) Disposition and metabolism of [14C]loperamide in rats. Eur $\mathrm{J}$ Drug Metab Pharmacokinet 4:199-206 PMID: 535599

38. Yoshida K, Nambu K, Arakawa S, Miyazaki H, Hashimoto M (1979) Metabolites of loperamide in rats. Biomed Mass Spectrom 6:253-259 PMID: 476289

39. He H, Sadeque A, Erve JC, Wood AJ, Hachey DL (2000) Quantitation of loperamide and N-demethyl-loperamide in human plasma using electrospray ionization with selected reaction ion monitoring liquid chromatography-mass spectrometry. J Chromatogr B Biomed Sci Appl 744:323-331 PMID: 10993521

40. Tayrouz Y, Ganssmann B, Ding R, Klingmann A, Aderjan R, Burhenne J, Haefeli WE, Mikus G (2001) Ritonavir increases loperamide plasma concentrations without evidence for Pglycoprotein. involvement. Clin Pharmacol Ther 70:405-414

41. Kim KA, Chung J, Jung DH, Park JY (2004) Identification of cytochrome $\mathrm{P} 450$ isoforms involved in the metabolism of 
loperamide in human liver microsomes. Eur J Clin Pharmacol 60:575-581. doi:10.1007/s00228-004-0815-3 PMID: 15365656

42. Lecomte JM, Costentin J, Vlaiculescu A, Chailet P, MarcaisCollado H, Llorens-Cortes C, Leboyer M, Schwartz JC (1986) Pharmacological properties of acetorphan, a parenterally active enkephalinases inhibitor. J Pharmacol Exp Ther 237:937-944 PMID: 3519939

43. Pirmohamed M, James S, Meakin S, Green C, Scott AK, Walley TJ, Farrar K, Park BK, Breckenridge AM (2004) Adverse drug reactions as cause of admission to hospital: prospective analysis of 18820 patients. BMJ 329:15-19 PMID: 15231615

44. Beijer HJ, de Blaey CJ (2002) Hospitalizations caused by adverse drug reactions (ADR): a meta-analysis of observational studies. Pharm World Sci 24:46-54 PMID: 12061133

45. Gallelli L, Colosimo M, Pirritano D, Ferraro M, De Fazio S, Marigliano NM, De Sarro G (2007) Retrospective evaluation of adverse drug reactions induced by nonsteroidal anti-inflammatory drugs. Clin Drug Investig 27:115-122 PMID: 17217316

46. Gallelli L, Ferreri G, Colosimo M, Pirritano D, Guadagnino L, Pelaia G, Maselli R, De Sarro GB (2002) Adverse drug reactions to antibiotics observed in two pulmonology divisions of Catanzaro, Italy: a six-year retrospective study. Pharmacol Res 46:395-400. doi:10.1016/S1043661802002104 PMID: 12419643

47. Gallelli L, Ferreri G, Colosimo M, Pirritano D, Flocco MA, Pelaia G, Maselli R, De Sarro GB (2003) Retrospective analysis of adverse drug reactions to bronchodilators observed in two pulmonary divisions of Catanzaro, Italy. Pharmacol Res 47:493-499. doi:10.1016/S1043-6618(03)00003-3 PMID: 12742002

48. Gallelli L, Nardi M, Prantera T, Barbera S, Raffaele M, Arminio D, Pirritano D, Colosimo M, Maselli R, Pelaia G, De Gregorio P, De Sarro GB (2004) Retrospective analysis of adverse drug reactions induced by gemcitabine treatment in patients with nonsmall cell lung cancer. Pharmacol Res 49:259-263. doi:10.1016/j. phrs.2003.10.001 PMID: 14726222

49. Zhang M, Holman CD, Price SD, Sanfilippo FM, Preen DB, Bulsara MK (2009) Comorbidity and repeat admission to hospital for adverse drug reactions in older adults: retrospective cohort study. BMJ 338:a2752. doi:10.1136/bmj.a2752 PMID: 19129307

50. Schiller LR, Santa Ana CA, Morawski SG, Fordtran JS (1984) Mechanism of the antidiarrheal effect of loperamide. Gastroenterology 86:1475-1480 PMID: 6714575

51. Kachel G, Ruppin H, Hagel J, Barina W, Meinhardt M, Domschke W (1986) Human intestinal motor activity and transport: effects of a synthetic opiate. Gastroenterology 90:85-93 PMID: 3940260

52. Sninsky CA, Davis RH, Clench MH, Thomas KD, Mathias JR (1986) Effect of lidamidine hydrochloride and loperamide on gastric emptying and transit of the small intestine: a double-blind study. Gastroenterology 90:68-73 PMID: 3940258

53. De Fazio S, Gallelli L, De Siena A, De Sarro G, Scordo MG (2008) Role of CYP3A5 in abnormal clearance of methadone. Ann Pharmacother 42:893-897 PMID: 18460585 